\title{
Scaling of Supply Voltage in Design of Energy Saver FIR Filter on 28nm FPGA
}

\author{
Bishwajeet Pandey ${ }^{1}$, Vishal Jain ${ }^{2}$, Rashmi Sharma ${ }^{3}$, Mragang Yadav ${ }^{4}$ \\ and D M Akbar Hussain ${ }^{5}$ \\ ${ }^{1,3,4}$ Center of Energy Excellence, Gyancity Research Lab \\ Gurgaon, India \\ ${ }^{2}$ Bharati Vidyapeeth's Institute of Computer Applications and Management \\ (BVICAM), Delhi, India \\ ${ }^{5}$ Department of Energy Technology, Aalborg University \\ Esbjerg, Denmark \\ gyancity@gyancity.com,drvishaljain83@gmail.com, \\ rashmisharma1505@gmail.com,mragangjec@gmail.com,akh@et.aau.dk
}

\begin{abstract}
In this work, we are going to analyze the effect of main supply voltage, auxiliary supply voltage, local voltage of different power bank, and supply voltage in GTX transceiver and BRAM on power dissipation of our FIR design using Verilog during implementation on $28 \mathrm{~nm}$ FPGA. We have also taken three different level of voltage with 16 IO standards and we get three different power analysis for each IO Standards. IO power dissipation of FIR filter is $150 \mathrm{~mW}$ with SSTL_18_II IO standard. When we migrate our design with HSTL_I, HSUL_12, LVCMOS15, LVTTL, MOBILE_DDR, and PCI33_3IO standards then there is $53.33 \%, 86 \%, 90.67 \%, 65.33 \%, 52 \%$, and $48.67 \%$ reduction in IO power dissipation of FIR Filter design on CSG324 package of Artix-7 FPGA family.
\end{abstract}

Keywords: Supply Voltage, Input Voltage, Output Voltage, Auxiliary Voltage, Power Dissipation, Energy Efficient, FIR Filter

\section{Introduction}

VCCINT supply power with internally connected metallization in chip. Internal connection have to ensure good decoupling capacitors, minimum IR drop, and lesser noise on the power rails. VCCAUX bumps on the die connect with common metal interconnect. This interconnect has a common connection on the laminate package. VCCO pins tied together for pins in the same bank [1]. VCCO33, VCCO25, VCCO18, VCCO15, VCCO135 and VCCO12 are 6 difference VCCO pins for six following voltage of bank $3.3 \mathrm{~V}, 2.5 \mathrm{~V}, 1.8 \mathrm{~V}, 1.5 \mathrm{~V}, 1.35 \mathrm{~V}$ and $1.2 \mathrm{~V}$ respectively. We have also taken three different level of voltage for three different power analysis with 16 IO Standards of 7 different family. For example, minimum voltage is $0.95 \mathrm{~V}$, average voltage is $1.0 \mathrm{~V}$ and maximum voltage is $1.05 \mathrm{~V}$ for VCCINT as shown in Table 1. SSTL IO standards family is the most power hungry IO standards. LVCMOS is the most energy efficient IO standards for our FIR filter design on FPGA. Power dissipation of other 5 IO standards family like, HSTL, HSUL, LVTLL, MOBILE_DDR and PCI33_3 give intermediate results in terms of power. 


\section{Table 1. Scaling of Voltage in FIR Filter on 28nm FPGA}

\begin{tabular}{|c|c|c|c|}
\hline Voltage & Minimum & Average & Maximum \\
\hline Vccint & 0.950 & 1.000 & 1.050 \\
\hline Vccaux & 1.710 & 1.800 & 1.890 \\
\hline Vcco33 & 3.000 & 3.300 & 3.450 \\
\hline Vcco25 & 2.380 & 2.500 & 2.630 \\
\hline Vcc018 & 1.710 & 1.800 & 1.900 \\
\hline Vcco15 & 1.430 & 1.500 & 1.580 \\
\hline Vcco135 & 1.300 & 1.350 & 1.400 \\
\hline Vcco12 & 1.140 & 1.200 & 1.260 \\
\hline Vccaux_io & 1.710 & 1.800 & 1.890 \\
\hline Vccbram & 0.950 & 1.000 & 1.050 \\
\hline MGTAVcc & 0.950 & 1.000 & 1.050 \\
\hline MGTAVtt & 1.140 & 1.200 & 1.260 \\
\hline Vccadc & 1.710 & 1.800 & 1.890 \\
\hline
\end{tabular}

In 7 series FPGA, average VCCINT, VCCAUX, VCCBRAM, and VCCADC voltage for power analysis are $1.0 \mathrm{~V}, 1.8 \mathrm{~V}, 1.0 \mathrm{~V}$ and $1.8 \mathrm{~V}$ respectively as shown in Table 1 . The recommended GTX transceiver power up sequence is VCCINT, MGTAVCC, MGTAVTT. Whereas, the recommended GTX transceiver power down sequence is MGTAVTT, MGTAVCC, VCCINT. The current and voltage associated with MGTAVTT, MGTAVCC are shown in Figure 1.

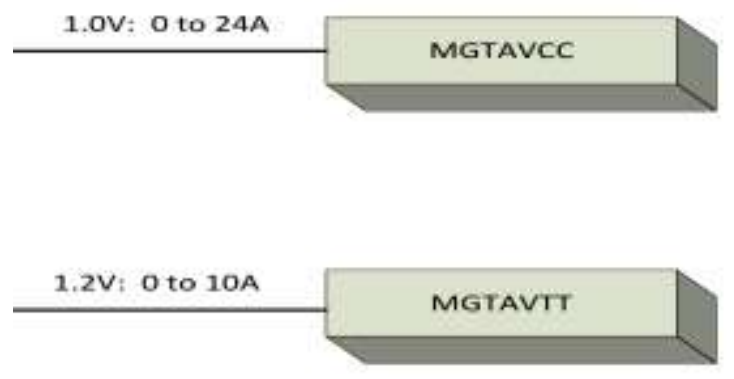

Figure 1. Xilinx MGT Reference Design [2]

VCCINT, VCCAUX, and VCCBRAM capacitors are listed as the quantity per device, while VCCO capacitors are listed as the quantity per I/O bank [3]. There are 41,600 FF, 90 DSP and 210 IO available on CSG324 package of Artix-7 FPGA family. Our current design of FIR filter, is using flip-lop (FF), digital signal processing (DSP) blocks and input/output (IO) port available on Artix-7 FPGA as shown in Table 2.

Table 2. Resource Availability and Usage by FIR Filter Design

\begin{tabular}{|l|l|l|}
\hline Resource & Utilization & Available \\
\hline FF & 48 & 41600 \\
\hline DSP & 9 & 90 \\
\hline IO & 28 & 210 \\
\hline
\end{tabular}

Our design is using only $1 \%$ (48 out of 41600 ), $10 \%$ (9 out of 90) and 13\% (28 out of 210) FF, DSP and IO as shown in Figure 2 and Table 2. 


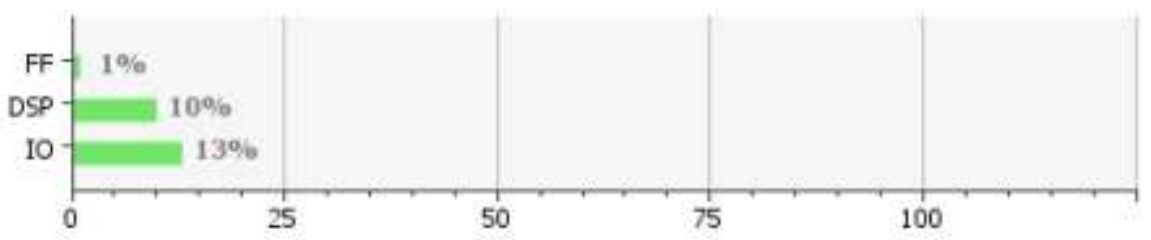

Figure 2. Resource Availability and Usage in Artix-7 FPGA

\section{Related Work}

Scaling of supply voltage on $28 \mathrm{~nm} 7$ series FPGA means variation of voltage between $0.95 \mathrm{~V}$ to $1.5 \mathrm{~V}$. Voltage scaling in this paper is variation of voltage between $0.95 \mathrm{~V}$ to $3.45 \mathrm{~V}$. In [4], energy efficient counter is developed with use of technique called voltage scaling. In [5], energy efficient mobile battery charge controller sensor is developed with voltage scaling. Voltage scaling is also used in FPGA based design of cyclic redundancy check [6], flip-flop [7] and Wi-Fi Ah Channel enable ALU [8]. [9] Investigates the possibility of reductions possible in commercially available FPGAs configured to support voltage, frequency and logic scalability combined with power gating. Voltage and frequency scaling is based on in-situ detectors that allow the device to detect valid working voltage and frequency pairs at run-time while logic scalability is achieved with partial dynamic reconfiguration [9].

\section{Artix-7 FPGA}

Dynamic power is related to switching activity and clock frequency of design. For power analysis of our design, we have to create timing constraints and add that clock to our design. In this work, our waveform has $10 \mathrm{~ns}$ period, 0ns rising edge time and $5 \mathrm{~ns}$ falling edge time as shown in Figure 3.

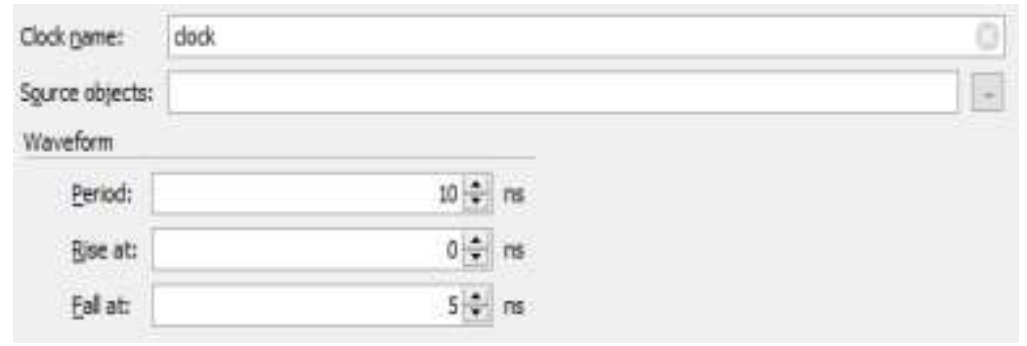

Figure 3. Clock Information of our FIR Filter Design

Table 3. Power Dissipation with Different IO Standards

\begin{tabular}{|l|r|}
\hline IO STANDARDS & $\begin{array}{c}\text { POWER DISSIPATION } \\
\text { (Watt) }\end{array}$ \\
\hline LVCMOS15 & 0.014 \\
\hline LVCMOS18 & 0.017 \\
\hline SSTL135_R & 0.021 \\
\hline SSTL15_R & 0.023 \\
\hline LVCMOS25 & 0.033 \\
\hline SSTL135 & 0.041 \\
\hline SSTL15 & 0.048 \\
\hline LVCMOS33 & 0.052 \\
\hline LVTTL & 0.052 \\
\hline HSTL_I & 0.07 \\
\hline
\end{tabular}




\begin{tabular}{|l|r|}
\hline MOBILE_DDR & 0.072 \\
\hline PCI33_3 & 0.077 \\
\hline SSTL_18_I & 0.09 \\
\hline HSUL_12 & 0.107 \\
\hline HSTL_II & 0.118 \\
\hline SSTL_18_II & 0.15 \\
\hline
\end{tabular}

When we are using LVCMOS15, IO Power dissipation of FIR filter is the lowest i.e., $14 \mathrm{~mW}$. Whereas, IO power dissipation of FIR filter is the highest i.e., $150 \mathrm{~mW}$ with SSTL_18_II IO standards as shown in Table 3. Other family of IO standards like LVTTL, HSTL_I, MOBILE_DDR, PCI33_3 and HSUL is taking $52 \mathrm{~mW}, 70 \mathrm{~mW}, 72 \mathrm{~mW}, 77 \mathrm{~mW}$ and $107 \mathrm{~mW}$ respectively as shown in Table 3 and Figure 4.

\section{IO POWER DISSIPATION IN FIR}

\section{FILTER}

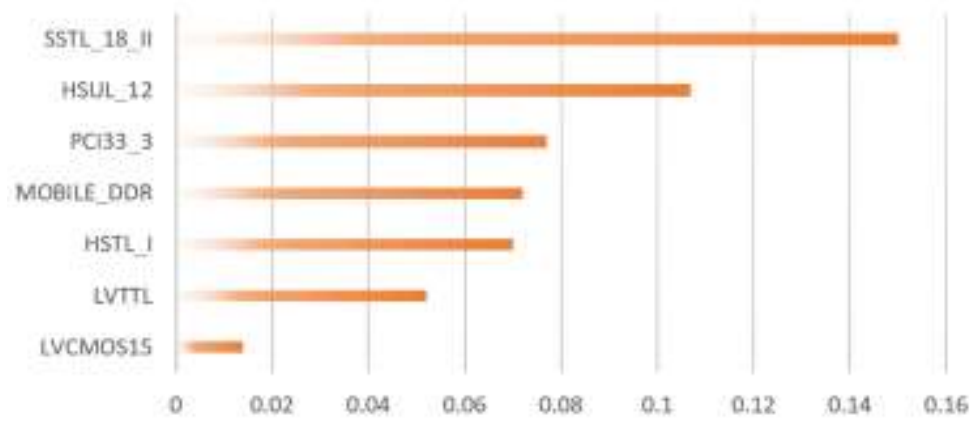

Figure 4. 10 Power Dissipation on Artix-7 FPGA with 7 IO Standards

A. Power Analysing Using LVCMOS18 For 3 Different Voltage Level: Minimum, Average, Maximum
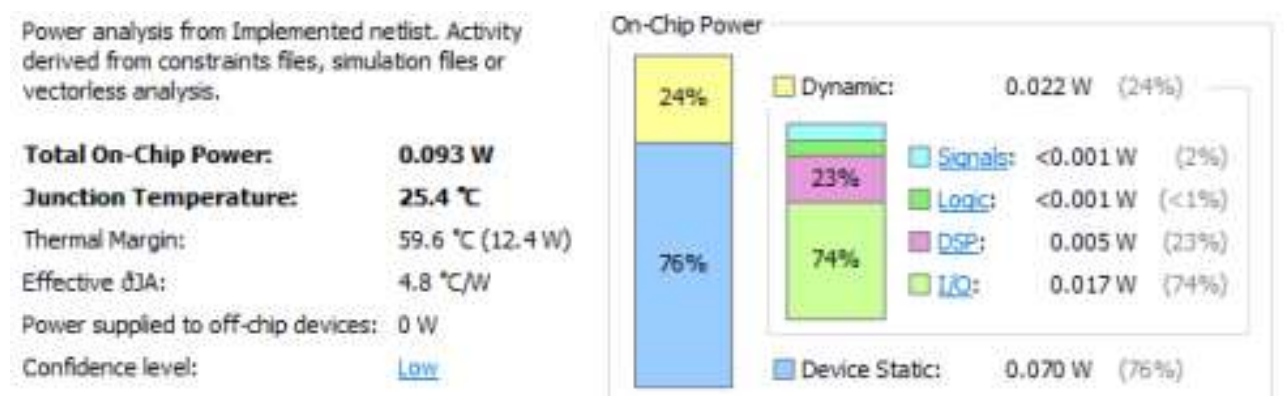

Figure 5. Power Analysis of FIR Filter for Minimum Voltage Level

For minimum voltage level, total on-chip power is $93 \mathrm{~mW}$ as shown in Figure 5. It increases to $98 \mathrm{~mW}$ for average voltage level as shown in Figure 5. It is $110 \mathrm{~mW}$ for maximum voltage level as shown in Figure 7. 
Power estimation from Synthesized netlist. Activity derived from constraints fles, simulation fles or vectorless andysis. Note: these early estmates can change after implementation.

Total On-Chip Power:

Junction Temperature:

Thermal Margn:

Effective t3A:

Power supplied to off-chip devices:

Confidence level:

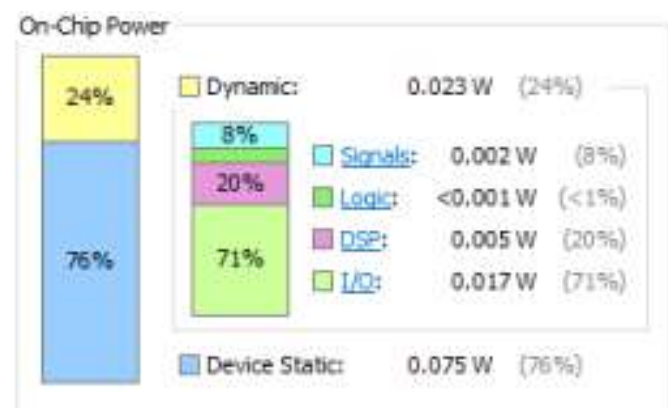

Figure 6. Power Analysis of FIR Filter for Average Voltage Level

Dynamic power is $22 \mathrm{~mW}, 23 \mathrm{~mW}$ and $25 \mathrm{~mW}$ for minimum, average and maximum voltage level as shown in Figure5-7

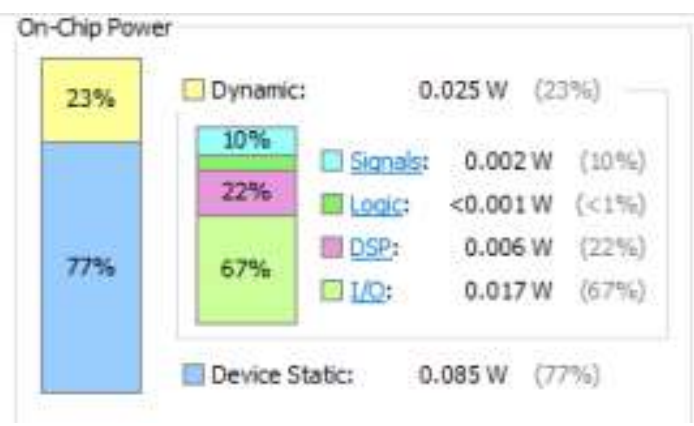

\section{Figure 7. Power Analysis of FIR Filter for Maximum Voltage Level}

B. Power Analysing Using HSTL_I For 3 Different Voltage Level: Minimum, Average, Maximum

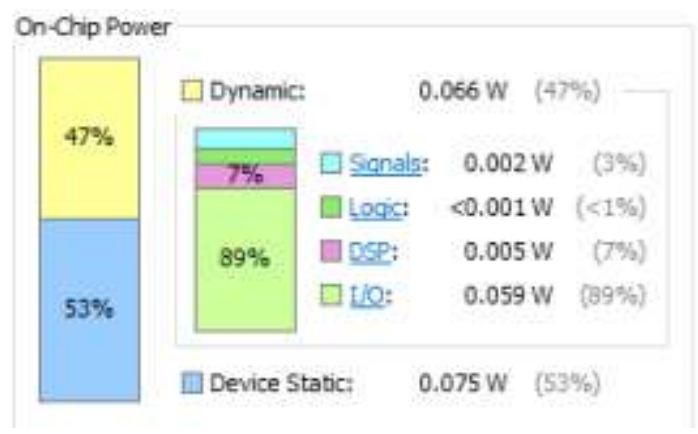

\section{Figure 8. Power Analysis of FIR Filter for Minimum Voltage Level}

Dynamic power is $66 \mathrm{~mW}$, power supplied to off-chip device is $66 \mathrm{~mW}$ as shown in Figure 8 . 

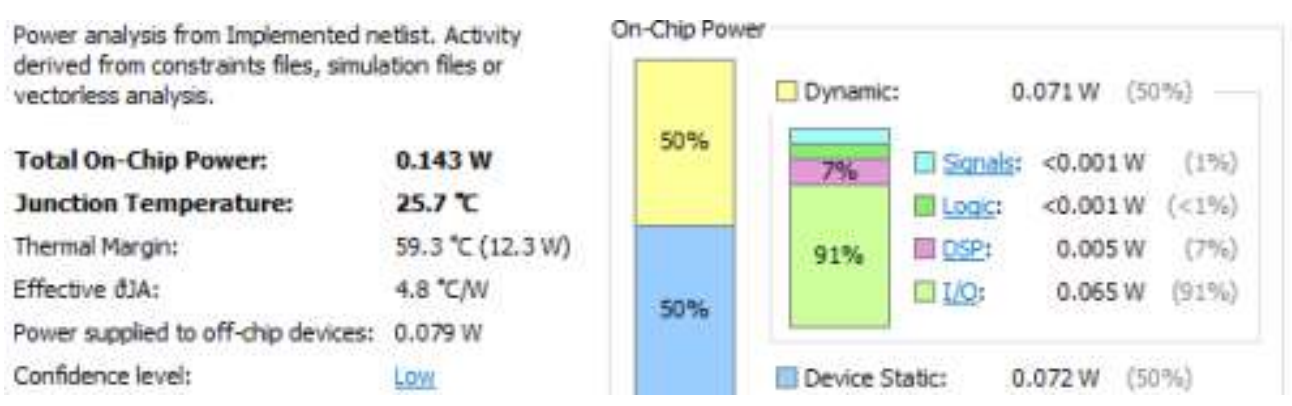

\section{Figure 9. Power Analysis of FIR Filter for Average Voltage Level}

Dynamic power is $71 \mathrm{~mW}$. Total on-chip power is $143 \mathrm{~mW}$ and power supplied to offchip device is $79 \mathrm{~mW}$ as shown in Figure 9.
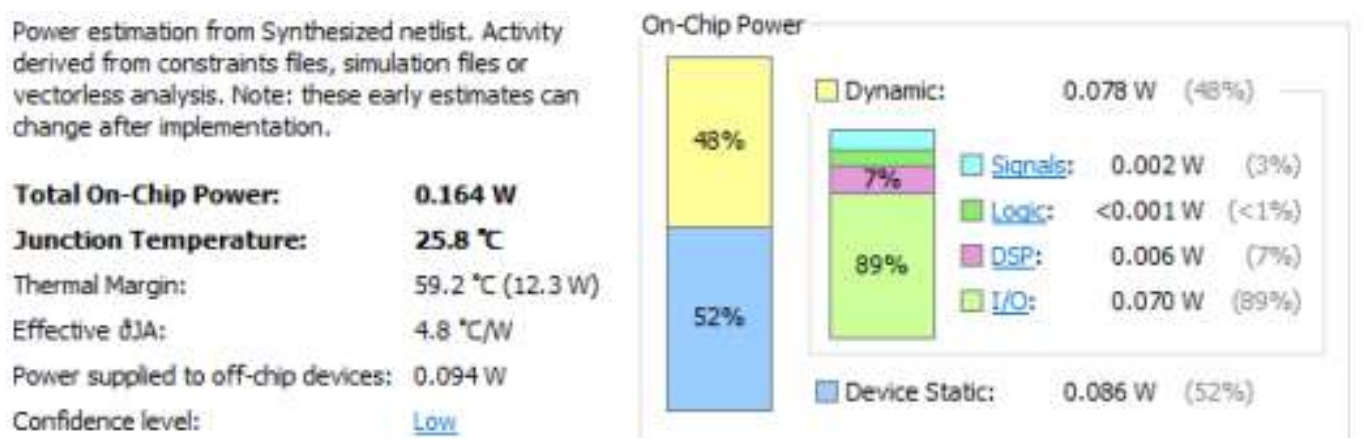

\section{Figure 10. Power Analysis of FIR Filter for Maximum Voltage Level}

For maximum voltage level, dynamic power is $71 \mathrm{~mW}$. Junction Temperature is $25.8^{\circ} \mathrm{C}$. Total on-chip power is $164 \mathrm{~mW}$ and power supplied to off-chip device is $79 \mathrm{~mW}$ as shown in Figure 10.

C. Power Analysing Using HSUL_12 For 3 Different Voltage Level: Minimum, Average, Maximum
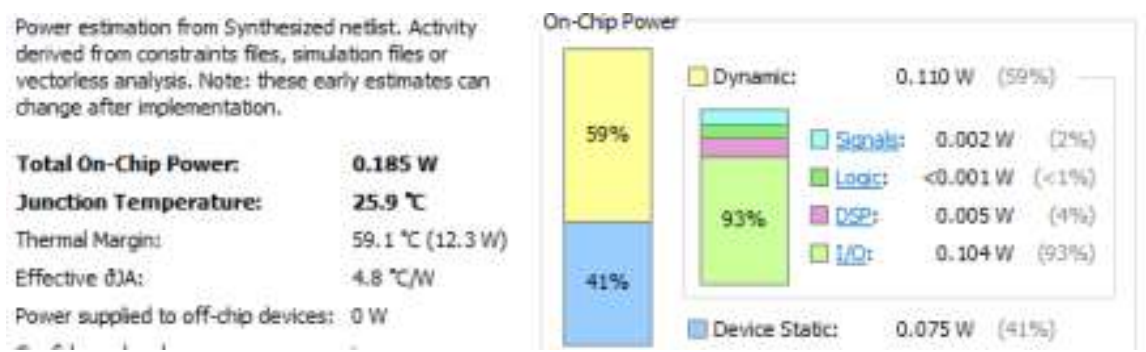

Figure 11. Power Analysis of FIR Filter for Minimum Voltage Level

For minimum voltage level, dynamic power is $110 \mathrm{~mW}$. Junction Temperature is $25.9^{\circ} \mathrm{C}$. Total on-chip power is $185 \mathrm{~mW}$ as shown in Figure 11. 

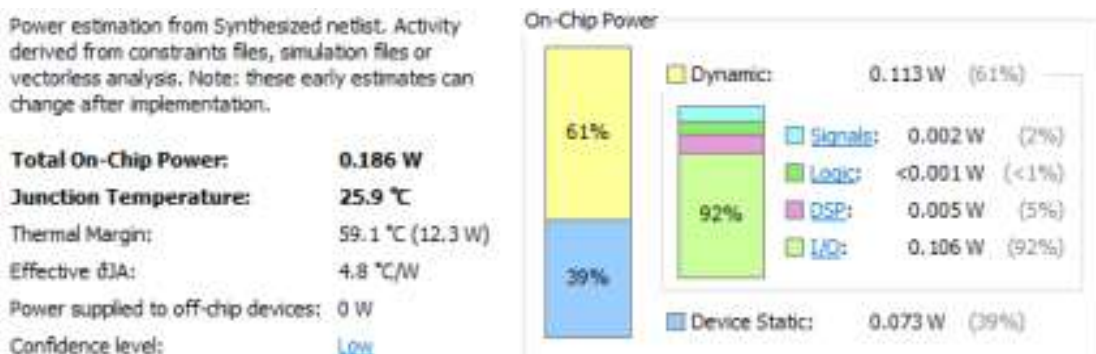

Figure 12. Power Analysis of FIR Filter for Average Voltage Level

For average voltage level, dynamic power is $113 \mathrm{~mW}$. Junction Temperature is $25.9^{\circ} \mathrm{C}$. Total on-chip power is $186 \mathrm{~mW}$ as shown in Figure 12.
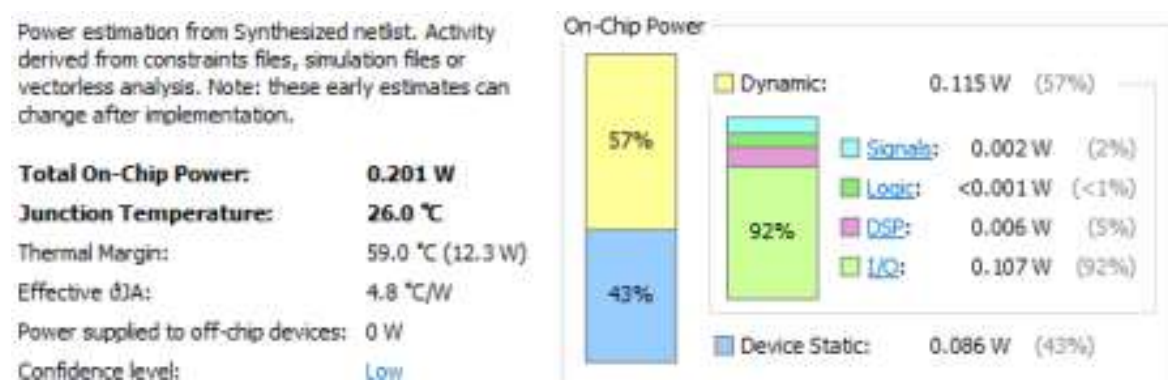

Figure 13. Power Analysis of FIR Filter for Maximum Voltage Level

For maximum voltage level, dynamic power is $115 \mathrm{~mW}$. Junction Temperature is $26.0^{\circ} \mathrm{C}$. Total on-chip power is $201 \mathrm{~mW}$ as shown in Figure 13.

D. Power Analysing Using LVCMOS15 For 3 Different Voltage Level: Minimum, Average, Maximum
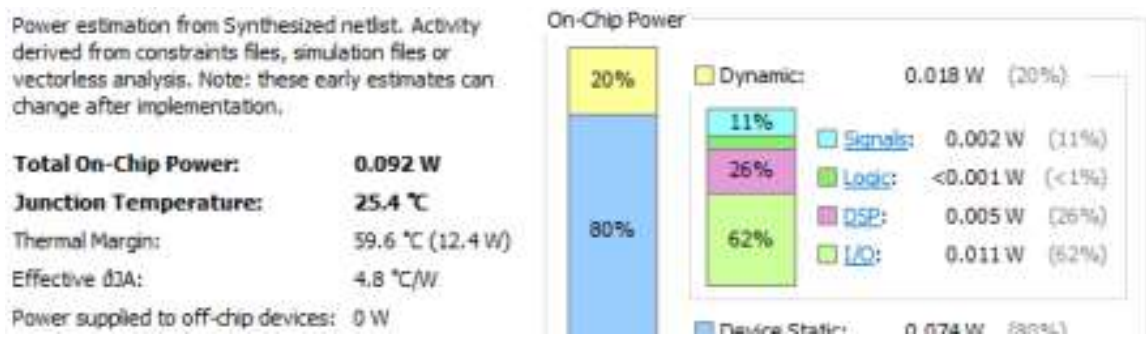

Figure 14. Power Analysis of FIR Filter for Minimum Voltage Level

For minimum voltage level, dynamic power is $18 \mathrm{~mW}$. Junction Temperature is $25.4^{\circ} \mathrm{C}$. Total on-chip power is $92 \mathrm{~mW}$ as shown in Figure 14.
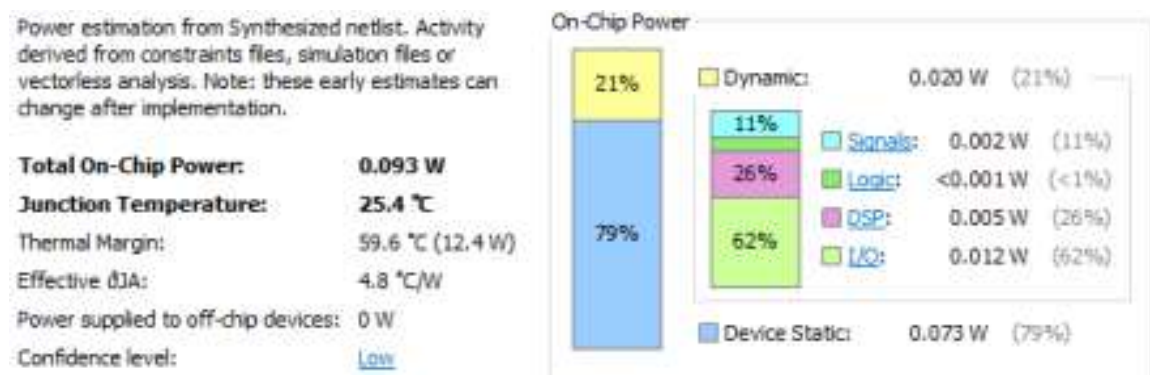

Figure 15. Power Analysis of FIR Filter for Average Voltage Level 
For average voltage level, dynamic power is $20 \mathrm{~mW}$. Junction Temperature is $25.4^{\circ} \mathrm{C}$. Total on-chip power is $93 \mathrm{~mW}$ as shown in Figure 15.
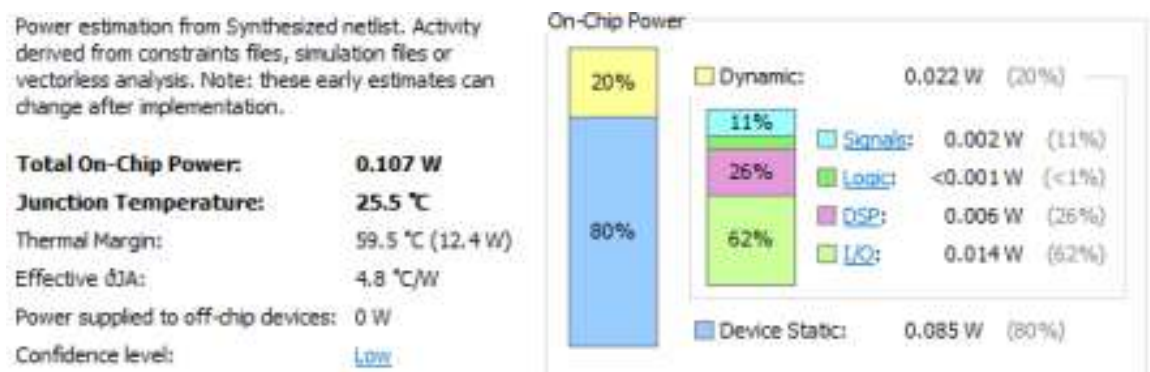

Figure 16. Power Analysis of FIR Filter for Maximum Voltage Level

For maximum voltage level, dynamic power is $22 \mathrm{~mW}$. Junction Temperature is $25.5^{\circ} \mathrm{C}$. Total on-chip power is $107 \mathrm{~mW}$ as shown in Figure 16.

E. Power Analysing Using LVTTL For 3 Different Voltage Level: Minimum, Average, Maximum
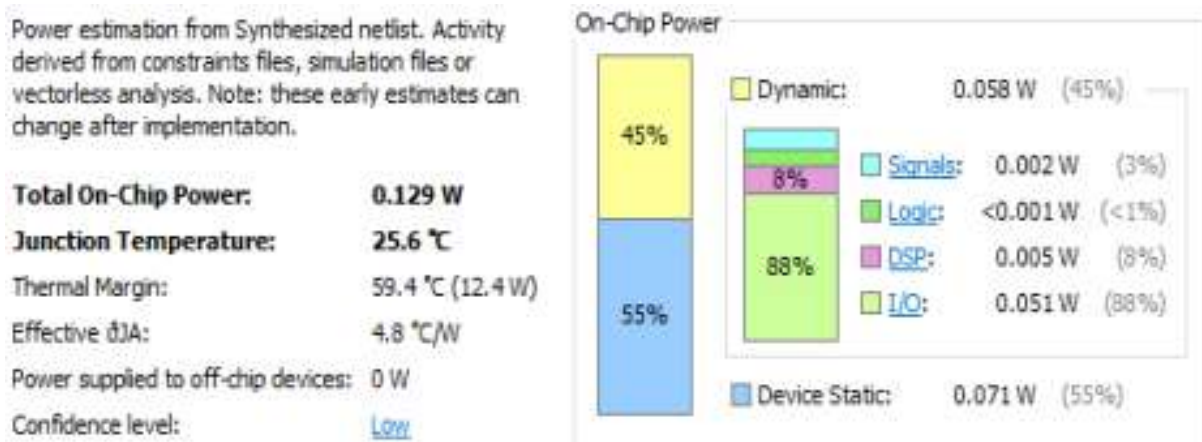

Figure 17. Power Analysis of FIR Filter for Minimum Voltage Level

For minimum voltage level, dynamic power is $58 \mathrm{~mW}$. Junction Temperature is $25.6^{\circ} \mathrm{C}$. Total on-chip power is $129 \mathrm{~mW}$ as shown in Figure 16.
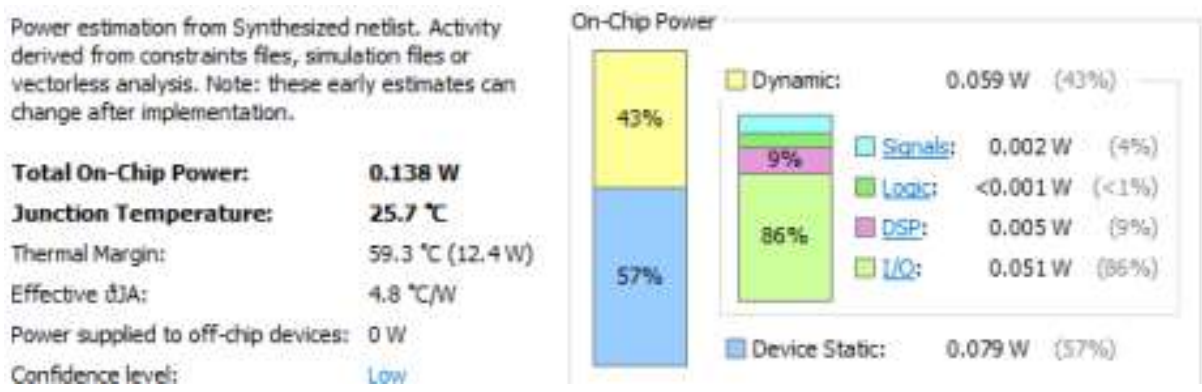

Figure 18. Power Analysis of FIR Filter for Average Voltage Level

For average voltage level, dynamic power is $59 \mathrm{~mW}$. Junction Temperature is $25.7^{\circ} \mathrm{C}$. Total on-chip power is $138 \mathrm{~mW}$ as shown in Figure 18. 
Power estmation from Synthesized nebist. Activity derived from constraints fles, smulation fies or vectorless andysis. Note: these early estimates can change after inplementatoon.

Total On-Chip Power:

Junction Temperature:

Thermal Margin:

Effective diA:

Power supplied to off-ctip devices: $0 \mathrm{~W}$

Confidence level:

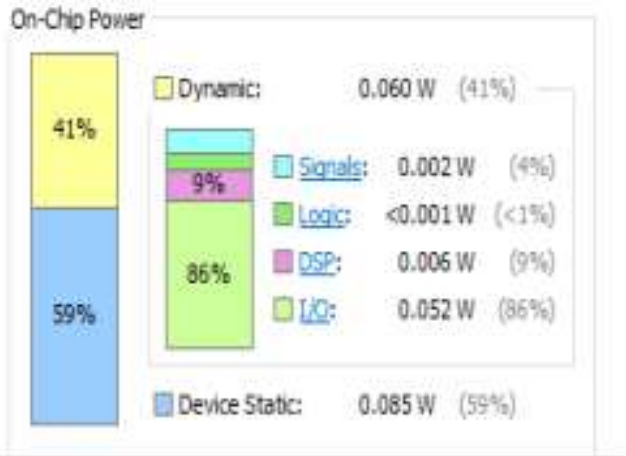

Figure 19. Power Analysis of FIR Filter for Maximum Voltage Level

For maximum voltage level, dynamic power is $60 \mathrm{~mW}$. Junction Temperature is $25.7^{\circ} \mathrm{C}$. Total on-chip power is $145 \mathrm{~mW}$ as shown in Figure 19.

F. Power Analysing Using MOBILE_DDR For 3 Different Voltage Level: Minimum, Average, Maximum

\begin{tabular}{|c|c|}
\hline \multicolumn{2}{|c|}{$\begin{array}{l}\text { Power estimation from Synthesized netist. Actwity } \\
\text { derived from constraints files, simulabion fles or } \\
\text { vectorless andlysis. Note: these early estimates can } \\
\text { change after implementation. }\end{array}$} \\
\hline Total On-Chip Power: & $0.15 \mathrm{w}$ \\
\hline Junction Temperature: & $25.7^{\circ} \mathrm{C}$ \\
\hline Thermal Margin: & $59.3 \times(12.4 w)$ \\
\hline Effective dJA: & $4.8^{\circ} \mathrm{CMN}$ \\
\hline Power suppled to off-chip devices: & ow \\
\hline Confiderce level: & Lovi \\
\hline
\end{tabular}

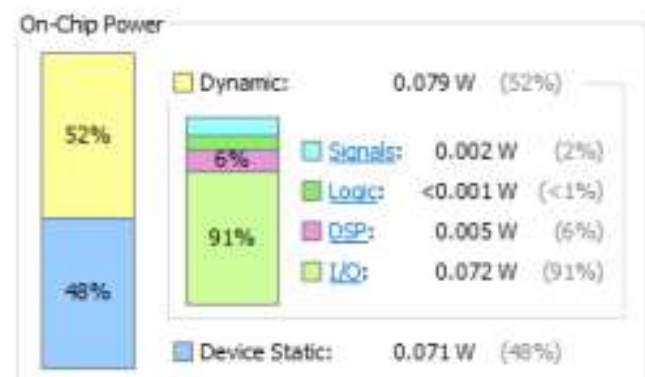

Figure 20. Power Analysis of FIR Filter for Minimum Voltage Level

For minimum voltage level, dynamic power is $79 \mathrm{~mW}$. Junction Temperature is $25.7^{\circ} \mathrm{C}$. Total on-chip power is $150 \mathrm{~mW}$ as shown in Figure 20.
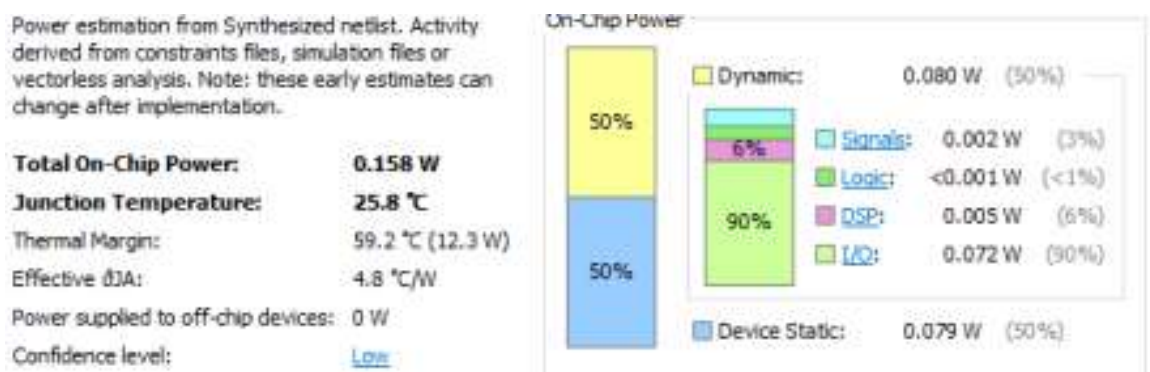

Figure 21. Power Analysis of FIR Filter for Average Voltage Level

For average voltage level, dynamic power is $80 \mathrm{~mW}$. Junction Temperature is $25.8^{\circ} \mathrm{C}$. Total on-chip power is $158 \mathrm{~mW}$ as shown in Figure 21. 

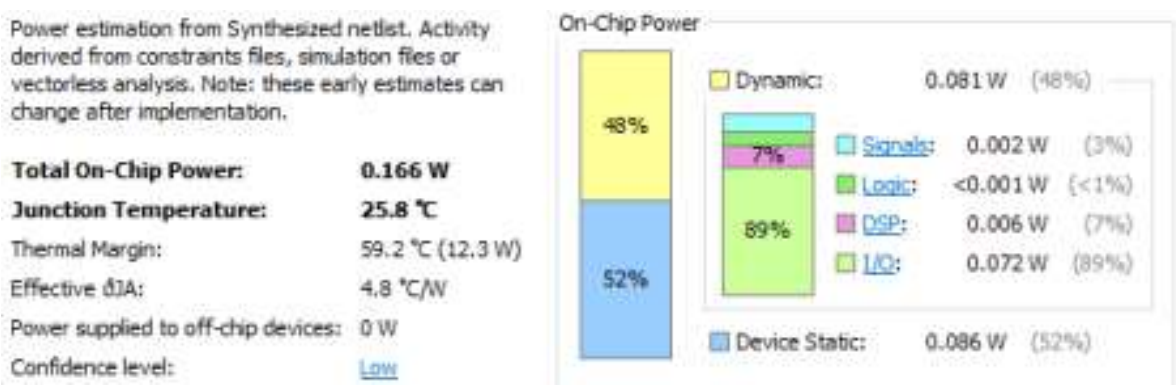

Figure 22. Power Analysis of FIR Filter for Maximum Voltage Level

For maximum voltage level, dynamic power is $81 \mathrm{~mW}$. Junction Temperature is $25.8^{\circ} \mathrm{C}$. Total on-chip power is $166 \mathrm{~mW}$ as shown in Figure 22.

G. Power Analysing Using PCI33_3 For 3 Different Voltage Level: Minimum, Average, Maximum
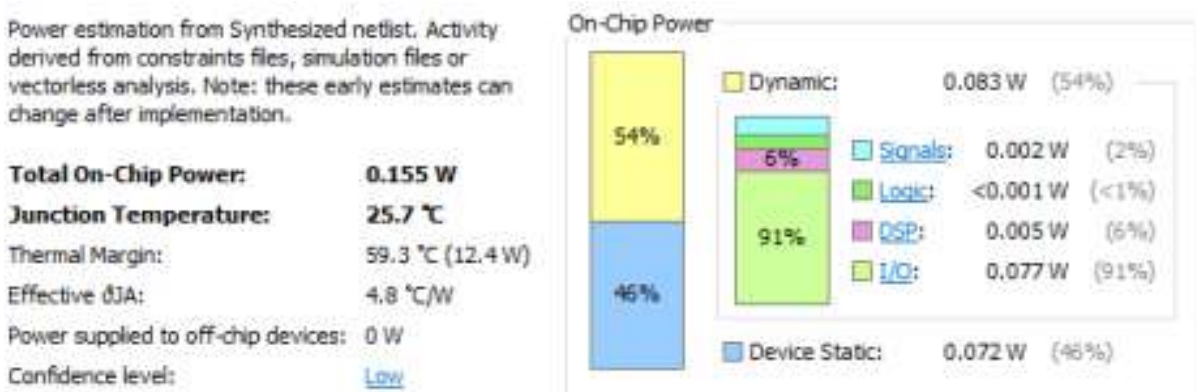

Figure 23. Power Analysis of FIR Filter for Minimum Voltage Level

For minimum voltage level, dynamic power is $83 \mathrm{~mW}$. Junction Temperature is $25.7^{\circ} \mathrm{C}$. Total on-chip power is $155 \mathrm{~mW}$ as shown in Figure 23.

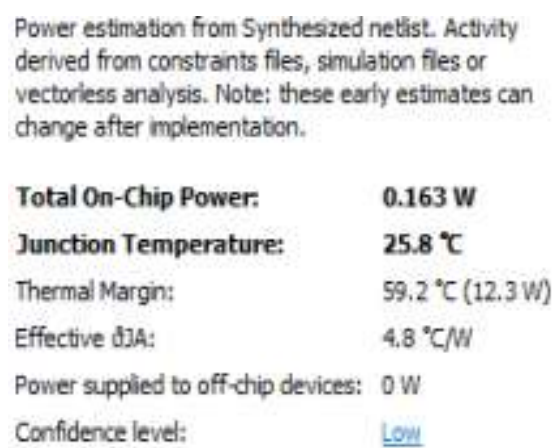

\section{Figure 24. Power Analysis of FIR Filter for Average Voltage Level}

For average voltage level, dynamic power is $84 \mathrm{~mW}$. Junction Temperature is $25.8^{\circ} \mathrm{C}$. Total on-chip power is $163 \mathrm{~mW}$ as shown in Figure 24. 

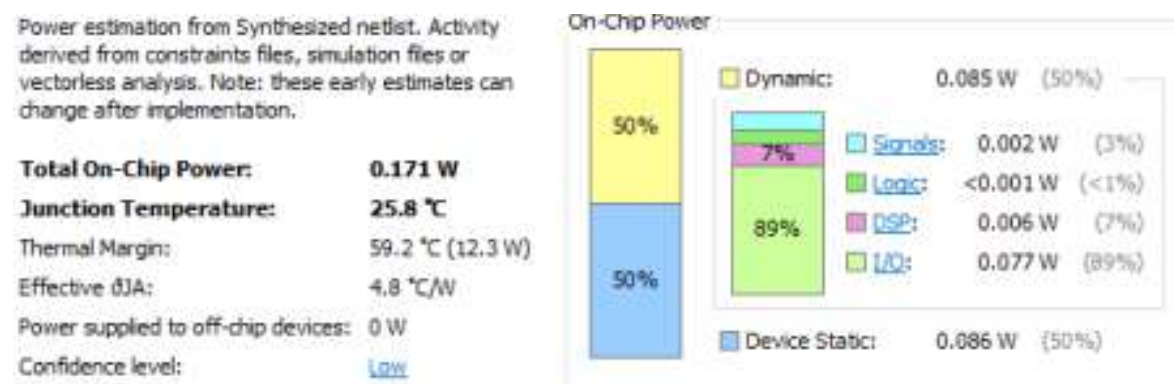

Figure 25. Power Analysis of FIR Filter for Maximum Voltage Level

For maximum voltage level, dynamic power is $85 \mathrm{~mW}$. Junction Temperature is $25.8^{\circ} \mathrm{C}$. Total on-chip power is $171 \mathrm{~mW}$ as shown in Figure 25.

H. Power Analysing Using SSTL_18_II For 3 Different Voltage Level: Minimum, Average, Maximum
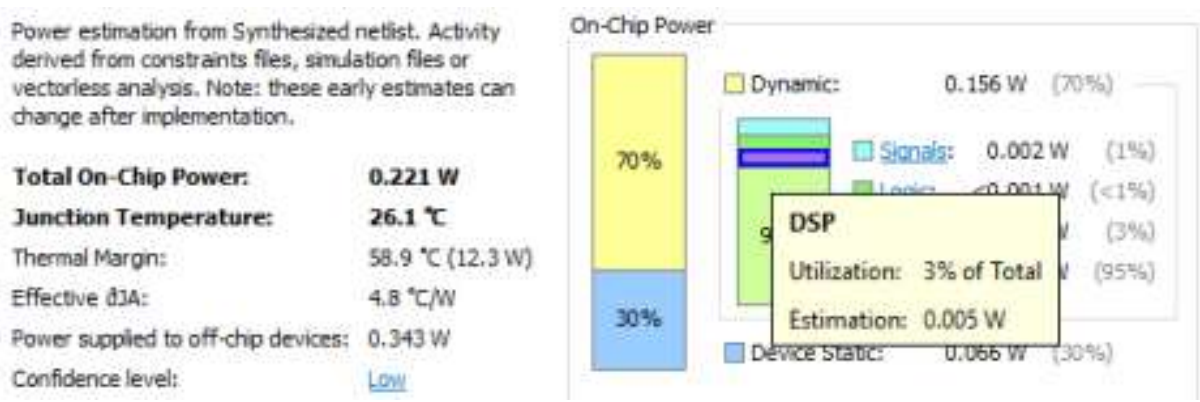

\section{Figure 26. Power Analysis of FIR Filter for Minimum Voltage Level}

For minimum voltage level, dynamic power is $156 \mathrm{~mW}$. Junction Temperature is $26.1^{\circ} \mathrm{C}$. Total on-chip power is $221 \mathrm{~mW}$ as shown in Figure 26.
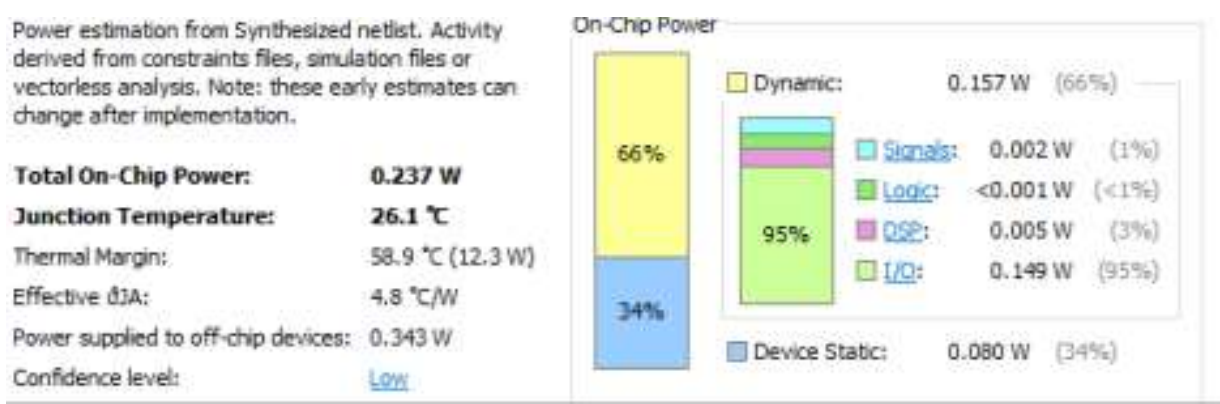

Figure 27. Power Analysis of FIR Filter for Average Voltage Level

For average voltage level, dynamic power is $157 \mathrm{~mW}$. Junction Temperature is $26.1^{\circ} \mathrm{C}$. Total on-chip power is $237 \mathrm{~mW}$ as shown in Figure 27. 


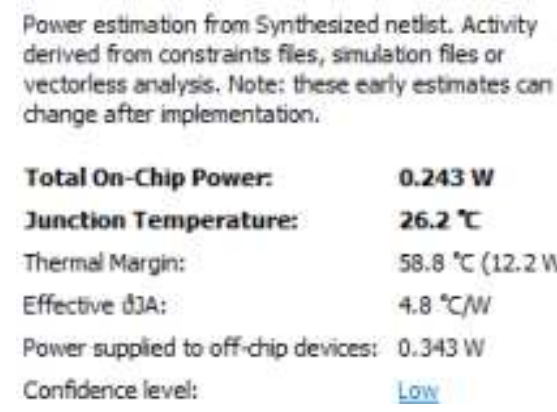

ton

Figure 28. Power Analysis of FIR Filter for Maximum Voltage Level

For maximum voltage level, dynamic power is $158 \mathrm{~mW}$. Junction Temperature is $26.2^{\circ} \mathrm{C}$. Total on-chip power is $243 \mathrm{~mW}$ as shown in Figure 28 .

\section{Conclusion}

We are able to reduce $91 \%$ power dissipation with usage of LVCMOS15 in place of power hungry IO standards of SSTL family. We have also verified that our design is able to operate on all three levels of voltage. Junction temperature is always below $30^{\circ} \mathrm{C}$. The IO power dissipation of HSTL, HSUL, MOBILE_DDR, PCI33_3 and LVTTL is in between power dissipation of both LVCMOS and SSTL.

\section{References}

[1] Are all of the VCCINT, VCCAUX, VCCAUX_IO, VCCO, or GND pins in the FPGA connected internally?, https://www.xilinx.com/support/answers/22338.html

[2] Xilinx Ultrascale MGT Reference Design, http://www.ti.com/lit/ug/tidu649/tidu649.pdf

[3] 7 Series FPGAs PCB Design Guide, https://www.xilinx.com/support/documentation/user_guides/ug483_7Series_PCB.pdf

[4] T. Gupta, et al. "Energy Efficient Counter Design Using Voltage Scaling On FPGA." Communication Systems and Network Technologies (CSNT), 2015 Fifth International Conference on. IEEE, (2015).

[5] S. M. Islam, et al. "Simulation of voltage scaling aware mobile battery charge controller sensor on FPGA." Advanced Materials Research. Vol. 893. Trans Tech Publications, (2014).

[6] P. Khaneja, et al. "Wireless Sensor Network Specific Voltage Scaling Based Energy Efficient Circuit Design for Cyclic Redundancy Check." Computational Intelligence and Communication Networks (CICN), 2015 International Conference on. IEEE, (2015).

[7] S. Singh, et.al. "Energy efficient flip flop design using voltage scaling on FPGA." Power Electronics (IICPE), 2014 IEEE 6th India International Conference on. IEEE, (2014).

[8] S. Singh, et al. "Simulation and Verification of Voltage and Capacitance Scalable 32-bit Wi-Fi Ah Channel Enable ALU Design on 40nm FPGA." Computational Intelligence and Communication Networks (CICN), 2015 International Conference on. IEEE, (2015).

[9] JL Nunez-Yanez, M. Hosseinabady, and A. Beldachi. "Energy optimization in commercial FPGAs with voltage, frequency and logic scaling." IEEE Transactions on Computers, vol. 65, no.5, (2016), pp. 14841493. 